\title{
Estudo da divergência genética por características morfológicas entre acessos de mentrasto (Ageratum conyzoides L.) coletados no Estado do Tocantins em diferentes épocas
}

\author{
CASTRO, H.G. ${ }^{1 *}$; SANTOS, G.R. ${ }^{1}$; MOMENTÉ, V.G. ${ }^{1}$; SILVA, D.J.H. ${ }^{2}$; RIBEIRO JÚNIOR, J.I. ${ }^{3}$ \\ ${ }^{1}$ Curso de Agronomia, Universidade Federal do Tocantins, Rua Badejós, Chácaras 69 e 72, lote 07, Caixa Postal \\ 66, CEP: 77402-970, Gurupi-Brasil *hguilhon@uft.edu.br ${ }^{2}$ Departamento de Fitotecnia, ${ }^{3}$ Departamento de \\ Informática, Universidade Federal de Viçosa, CEP: 36571-000, Viçosa-Brasil
}

\begin{abstract}
RESUMO: Este trabalho objetivou avaliar a divergência genética entre nove acessos de mentrasto (Ageratum conyzoides) por métodos multivariados utilizando caracteres morfológicos, em quatro épocas de colheita. Os nove acessos de mentrasto foram obtidos de plantas que ocorrem naturalmente nas cinco regiões climáticas do Estado do Tocantins. Em cada época de colheita foram avaliadas as características como biomassa fresca da parte aérea, biomassa seca, área foliar, número de folhas, floração e altura. Pela análise de agrupamento (método de Tocher) foram formados dois grupos na primeira e quarta épocas de colheita, três grupos na segunda época e quatro grupos na terceira época de colheita. Observou-se variação na constituição dos grupos pelos acessos nas épocas de colheita. A divergência genética entre acessos de mentrasto, avaliada por caracteres morfológicos, foi influenciada pelo estádio de desenvolvimento da espécie. A existência de variabilidade entre os acessos coletados em diferentes localidades fornece subsídio para a coleta sistematizada de germoplasma em A. conyzoides no Estado do Tocantins.
\end{abstract}

Palavras-chave: recursos genéticos vegetais, divergência genética, Ageratum conyzoides, métodos multivariados

\begin{abstract}
Genetic divergence study by morphologic traits among mentrasto (Ageratum conyzoides L.) accessions collected in the state of Tocantins in different period. This study aimed to analyze the genetic divergence among nine mentrasto (Ageratum conyzoides) accessions by multivariate methods using morphologic traits for four harvesting periods. The nine accessions of mentrasto were obtained from plants that occur naturally in five climatic regions of the state of Tocantins. At each harvesting period, the following traits were evaluated: fresh biomass of the aerial part, dry biomass, leaf area, number of leaves, flowering and height. The grouping analysis (Tocher's method) identified two groups, in the first and fourth harvest periods, three groups in the second harvest period and four groups in the third harvest period. Variation was observed for the group constitutions among the different harvesting periods. The genetic divergence among mentrasto accessions, evaluated by morphologic traits, was influenced by developmental stage of specie. The existence of genetic variability among accessions from different regions supports the systematic collection of $A$. conyzoides germplasm in the state of Tocantins.
\end{abstract}

Key words: plant genetic resources, genetic divergence, Ageratum conyzoides, multivariate methods

\section{INTRODUÇÃO}

A perda de recursos genéticos é denominada erosão genética. Algumas causas dessa perda são o aumento da população, a extensão da fronteira agrícola, a adoção de germoplasma elite responsável pela uniformização genética dos cultivos e a destruição dos centros de variabilidade genética. Essa perda de recursos fitogenéticos coloca em evidência a necessidade da conservação e caracterização (Cabral et al., 2002; Castro et al., 2005; Botrel et al., 2006).

Estudos acerca da divergência genética são importantes em programas de melhoramento, por fornecerem parâmetros para identificação dos genitores que, quando cruzados, possibilitam maior

Recebido para publicação em 15/05/2009

Aceito para publicação em 25/07/2010

Rev. Bras. PI. Med., Botucatu, v.13, n.1, p.24-29, 2011. 
efeito heterótico na progênie e maior probabilidade de recuperar genótipos superiores nas gerações segregantes. A avaliação da divergência genética também é de grande valia no estudo da evolução das espécies, uma vez que provê informações a respeito dos recursos disponíveis e auxilia na localização e no intercâmbio desses recursos (Silva et al., 2001; Castro et al., 2002; Castro et al., 2004; Arriel et al., 2007).

O mentrasto (Ageratum conyzoides L.), família Asteraceae, é planta nativa da América tropical com adaptação a diversas condições ambientais, estabelecendo-se em várias regiões de clima tropical e subtropical do mundo. Nos países onde ocorre, pode ser encontrada desde o nível do mar até 3000 metros de altitude, quando a temperatura está acima de $10^{\circ} \mathrm{C}$ (Castro et al., 2008).

A. conyzoides possui uso medicinal difundido pela população no Brasil e em outros países. $O$ consumo da droga vegetal dessa espécie tem aumentado a partir da verificação da eficácia como analgésico e antiinflamatório no tratamento da artrose e da inclusão na lista da Central de Medicamentos (Marques Neto et al., 1988).

Estudos realizados com o óleo essencial da espécie em ratos mostraram que o mesmo possui significante atividade analgésica, antiinflamatória e antipirética, não sendo observada toxicidade gástrica. A presença de alcalóides com ação vaso constritora é atribuído efeito antiinflamatório, analgésico e cicatrizante (Menut et al., 1993; Abena et al., 1996; Magalhães et al., 1997; Okunade, 2002). O precoceno, um dos principais constituintes do óleo essencial de A. conyzoides, causa metamorfose prematura em diversas espécies de insetos, levando à formação de adultos estéreis (Borthakur et al., 1987; Gonzalez et al., 1991).

Este trabalho teve por objetivo estudar a divergência genética entre acessos de mentrasto por características morfológicas, provenientes de diferentes regiões geográficas do Estado do Tocantins, cultivados nas mesmas condições edafoclimáticas.

\section{MATERIAL E MÉTODO}

\section{Origem do material utilizado}

Foram coletados nove acessos de mentrasto (A. conyzoides), obtidos de plantas que ocorrem naturalmente nas cinco regiões climáticas do Estado do Tocantins, segundo o método de Thornthwaite (Secretaria do Planejamento e Meio Ambiente Diretoria de Zoneamento Ecológico-Econômico, 2003) (B1wA a - clima úmido com moderada deficiência hídrica; B2rA'a - clima úmido com pequena ou nula deficiência hídrica; C2rA'a - clima úmido subúmido com pequena deficiência hídrica; C2wA a - clima úmido subúmido com moderada deficiência hídrica;
C1dA a - clima subúmido seco com moderada deficiência hídrica).

Os acessos foram coletados nos seguintes municípios, com as respectivas coordenadas geográficas e regiões climáticas: Formoso do Araguaia (FOR) (1147'48" sul e 4931'44" oeste, com altitude de $240 \mathrm{~m}$ ) (B2rA a'), Gurupi (GUR) (11\%43'45" sul e 490.'07" oeste, com altitude de $287 \mathrm{~m}$ ) (B1wA'a), Aliança do Tocantins (ALI) (1118'22" sul e 4856'09" oeste, com altitude de $333 \mathrm{~m}$ ) (B1wA'a), Ananás (ANA) (0621'55" sul e 480.'22" oeste, com altitude de $220 \mathrm{~m}$ ) (C2rA'a'), Natividade (NAT) (11ㄴ.42'35" sul e 47ㄴ3'24" oeste, com altitude de $323 \mathrm{~m}$ ) (C2wA'a),

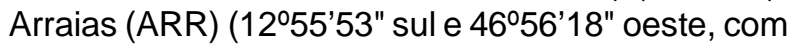
altitude de $682 \mathrm{~m})$ (C1dAa), Novo Alegre (NOV) (1255'52" sul e 463' $25^{\circ}$ " oeste, com altitude de 539 m) $(\mathrm{C} 1 \mathrm{dA} \cdot \mathrm{a})$, Taguatinga do Tocantins (TAG) (12²4'14" sul e 46으' '10" oeste, com altitude de 599 m) (C1dA,a) e Combinado (COM) (12\%47'31" sul e 46을' 20 "oeste, com altitude de $383 \mathrm{~m}$ ) (C1dAa). As exsicatas dos acessos coletados foram depositadas no herbário da Universidade Federal do Tocantins com os números: ANA-9352, COM- 9353, TAG- 9354, NOV- 9355, GUR- 9356, ARR- 9357, FOR9358, ALI- 9359 e NAT- 9360.

A coleta das sementes (capítulos) foi realizada em plantas individuais nativas em cada município. Em cada área foram coletadas sementes de 15 plantas e, posteriormente, retirada a mesma quantidade de sementes por planta para formação do "bulk" e a implantação do experimento. Após a coleta dos capítulos, as sementes foram postas para germinar em bandejas de isopor em casa de vegetação e o transplante foi feito aos 54 dias após a semeadura.

\section{Instalação do experimento e delineamento experimental}

O experimento foi conduzido em área experimental da Universidade Federal do TocantinsCampus de Gurupi. O delineamento experimental foi o inteiramente casualizado em esquema de parcela subdividida, com três repetições. As parcelas foram constituídas por nove acessos de mentrasto (tratamento principal) e as subparcelas por quatro épocas de amostragem. A unidade experimental foi constituída por um vaso de cinco litros com três plantas.

As épocas de amostragem foram espaçadas em intervalos de 21 dias. As amostras foram coletadas pelo método destrutivo, sendo avaliadas as características biomassa fresca da parte aérea, biomassa seca, área foliar, número de folhas, altura da planta e floração.

Para obtenção da área foliar total por planta foi, inicialmente, ajustada uma equação de regressão aos dados de comprimento (C), largura média (L) e área foliar (AF) das folhas, utilizando-se uma amostra de 30 folhas de diferentes tamanhos: $A F=-6,1287$ -

Rev. Bras. Pl. Med., Botucatu, v.13, n.1, p.24-29, 2011. 
4,6040 * $C+13,0141$ ** $L\left(R^{2}=95,92 \%\right)$. A equação de regressão ajustada foi utilizada na obtenção da área foliar por planta, a partir das medidas de comprimento e largura média das folhas em cada época de amostragem. No ajuste da equação de regressão, a área foliar das plantas foi obtida segundo o método dos contornos foliares (Benincasa, 1988).

Na determinação da floração foram utilizados os estádios de desenvolvimento floral $\mathrm{E} 0=$ plantas não-floridas (nota $=0$ ); $E 1$ = inflorescência em início de desenvolvimento $($ nota $=1)$; E2 = inflorescência com desenvolvimento máximo, não aberta $($ nota $=2)$; E3 = inflorescência aberta $($ nota $=3)$ e E4 = inflorescência em processo de escurecimento (nota $=4)$.

Foram realizadas quatro análises de agrupamento para cada época de amostragem, com o auxílio do programa GENES. Para cálculo da distância genética foi obtida a distância generalizada de Mahalanobis $\left(\mathrm{D}^{2}\right)$ e para delimitação dos grupos de dissimilaridade dos acessos foi adotado o método de Tocher (Cruz \& Regazzi, 1997).

A estimação da distância média dentro do grupo foi realizada calculando-se a média das distâncias entre pares de acessos de um mesmo grupo; a distância entre grupos foi estimada pela média das distâncias entre todos os pares de acessos dos grupos. Utilizou-se o critério de Singh (Singh, 1981) para identificar a contribuição relativa de cada característica para a diversidade entre os acessos.

A correlação de Spearman foi estimada para as distâncias genéticas obtidas entre diferentes épocas de colheita (Ribeiro Júnior, 2001).

\section{RESULTADO E DISCUSSÃO}

\section{Primeira época de colheita (21 dias após transplante)}

Dois grupos foram formados na primeira época de colheita (Tabela 1). O par mais divergente foi formado pelos acessos NAT e ARR, com $D^{2}=$ 131,8538, enquanto o par menos divergente foi constituído pelos acessos ALI e TAG, com $D^{2}=$
1,1497. Os acessos NAT e ARR também formaram o par mais divergente na segunda época de colheita. $A$ característica que menos contribuiu para a divergência genética nessa avaliação foi a massa seca, e a que mais contribuiu foi a massa fresca (Tabela 2).

\section{Segunda época de colheita (42 dias após transplante)}

Nesta época de colheita foram formados três grupos (Tabela 1). As distâncias médias intergrupos foram superiores para aquelas obtidas nas outras épocas de colheita (Tabela 3), demonstrando maior capacidade de distinção das características nessa época de amostragem. Castro et al. (2005) estudaram a estabilidade da divergência genética entre acessos de mentrasto coletados no Estado de Minas Gerais e também observaram alta capacidade de distinção das características na segunda época de colheita, aos 42 dias após transplante.

Comparando os grupos formados na primeira e segunda época de colheita, de forma geral observouse que houve consistência na composição dos grupos formados para essas épocas de amostragem (Tabela 1). Somente o acesso ARR que formava grupo com outros sete acessos na primeira época de colheita, passou a constituir um grupo isolado dos outros acessos na segunda época de colheita (Tabela 1).

Os acessos mais divergentes na segunda época de colheita foram NAT e ARR $\left(D^{2}=1000,0880\right)$, e o par menos divergente foi constituído pelos acessos ANA e TAG $\left(D^{2}=2,7541\right)$. De forma diferente, na terceira época de colheita os acessos ANA e TAG formaram o par mais divergente. A característica área foliar foi a que menos contribuiu para a divergência genética, e a característica massa seca, a que mais contribuiu (Tabela 2).

\section{Terceira época de colheita (63 dias após transplante) \\ Nesta época de colheita foram formados quatro grupos (Tabela 1), evidenciando maior potencial para diferenciação dos acessos do que nas outras épocas de colheita. Os acessos mais divergentes}

TABELA 1. Grupos de acessos similares de nove acessos de mentrasto (Ageratum conyzoides) estabelecidos por meio do método de Tocher, em quatro épocas de colheita.

\begin{tabular}{|c|c|c|c|c|}
\hline \multirow[b]{2}{*}{ Grupos } & \multicolumn{4}{|c|}{ Épocas de colheita } \\
\hline & 21 dat & 42 dat & 63 dat & 84 dat \\
\hline 1 & $\begin{array}{l}\text { ALI, TAG, GUR, } \\
\text { NOV, FOR, ANA, } \\
\text { ARR e COM. }\end{array}$ & $\begin{array}{l}\text { ALI, TAG, GUR, } \\
\text { NOV, FOR, ANA } \\
\text { e COM. }\end{array}$ & $\begin{array}{l}\text { ALI, GUR, NOV, } \\
\text { ARR, COM e } \\
\text { NAT. }\end{array}$ & $\begin{array}{l}\text { ALI, TAG, GUR, } \\
\text { NOV, NAT, ANA, } \\
\text { ARR e COM. }\end{array}$ \\
\hline 2 & NAT & ARR & FOR & FOR \\
\hline 3 & & NAT & ANA & \\
\hline 4 & & & TAG & \\
\hline
\end{tabular}

Rev. Bras. PI. Med., Botucatu, v.13, n.1, p.24-29, 2011. 
foram ANA e TAG $\left(D^{2}=196,8250\right)$, e o par menos divergente foi constituído pelos acessos GUR e ARR $\left(D^{2}=11,1195\right)$. Na quarta época de colheita o acesso TAG formou o par mais divergente com o acesso FOR e o acesso GUR formou o par menos divergente com o acesso ALI. A característica área foliar foi a que menos contribuiu para a divergência genética, e a característica massa seca, a que mais contribuiu (Tabela 2).

\section{Quarta época de colheita (84 dias após transplante)}

Dois grupos foram formados na quarta época de colheita (Tabela 1). O par de acessos mais divergente foi formado por FOR e TAG $\left(D^{2}=417,7948\right)$, e o menos divergente, pelos acessos GUR e ALI $\left(D^{2}=3,1027\right)$ que estão localizados na mesma região climática. A característica que mais contribuiu para a divergência genética entre os acessos nessa época de avaliação foi a massa seca, e a que menos contribuiu foi a altura (Tabela 2).

Comparando os grupos formados na terceira e quarta época de colheita, verificou-se redução no número de grupos formados. Os acessos ANA e TAG que formavam grupos isolados na terceira época de colheita ${ }_{1}$ passaram a constituir um grupo junto com outros seis acessos na quarta época de colheita (Tabela 1).

\section{Outros aspectos relacionados com a divergência entre os acessos}

Os acessos ALI, GUR, COM e NOV estiveram nos mesmos grupos nas quatro épocas de colheita, enfatizando as similaridades entre esses acessos com base no uso de características morfológicas. Os acessos que revelaram menor proximidade genética, utilizando características morfológicas, foram NAT e FOR que não formaram grupo juntos em nenhuma época de colheita (Tabela 1). Desta forma, os acessos NAT e FOR podem ser selecionados para orientar cruzamentos no programa de melhoramento de $A$. conyzoides.

Quanto à relação entre as divergências genéticas dos acessos e regiões climáticas, observouse que de forma geral acessos coletados na mesma região climática foram mais semelhantes (Tabela 1). Apenas os acessos ARR, na segunda época de colheita, e TAG, na terceira época de colheita, formaram grupos separados dos outros acessos coletados na mesma região climática (Tabela 1). Nesse sentido, na coleta de germoplasma de $A$. conyzoides deve-se priorizar a obtenção de acessos em regiões climáticas distintas visando à preservação de maior variabilidade genética da espécie.

Analisando a estrutura e a composição dos grupos formados nas diferentes épocas de colheita, pode-se observar variação na constituição dos grupos pelos acessos (Tabela 1). Com exceção dos grupos formados somente pelos acessos NAT e FOR, os outros grupos variaram na sua composição. Esse fato demonstra a inconsistência da composição dos grupos formados nas diferentes épocas de colheita.

Verificou-se tendência de redução da contribuição da biomassa fresca para a divergência genética em épocas de colheita mais tardias (Tabela 2), o que deve estar relacionada com a capacidade de absorção e manutenção do teor de umidade nos tecidos pelos acessos. Nesse sentido, no início do desenvolvimento os acessos de mentrasto apresentaram maiores diferenças em relação ao teor de umidade nos tecidos, com a tendência de redução gradativa dessa diferença até a última época de colheita, quando foi observada baixa contribuição para a divergência genética da biomassa fresca. Por outro lado, observou-se tendência de aumento da contribuição relativa da biomassa seca para a divergência genética em épocas de colheita mais tardias (Tabela 2), que deve estar relacionado com a eficiência fotossintética e a formação de fibra nos caules, folhas e flores, e com o acúmulo de lignina.

Em relação a contribuição da floração para a divergência genética, verificou-se tendência de redução dessa contribuição em épocas de colheita mais tardias, provavelmente pelo fato dos acessos iniciarem o estádio reprodutivo em épocas diferentes, sendo que na última época todos os acessos se encontravam em estádio de maturação de sementes (Tabela 2). Essa mesma tendência de redução da contribuição da floração para a divergência genética foi observada por Castro et al. (2005), em trabalho citado anteriormente.

Em relação à correlação das distâncias dos acessos entre as diferentes épocas de amostragem, foi observada correlação significativa apenas entre a

TABELA 2. Contribuição relativa percentual para a divergência genética $\left(D^{2}\right)$, analisada com base no critério de Singh (1981), das características massa fresca (MF), massa seca (MS), altura (ALT), floração (FLOR), área foliar (AF) e número de folhas (NF), de nove acessos de mentrasto (Ageratum conyzoides), em quatro épocas de colheita.

\begin{tabular}{ccccc}
\hline & \multicolumn{4}{c}{ Épocas de colheita } \\
\cline { 2 - 5 } Variáveis & $\mathbf{2 1}$ dat & $\mathbf{4 2}$ dat & $\mathbf{6 3}$ dat & $\mathbf{8 4}$ dat \\
\hline MF & 44,91 & 2,44 & 17,65 & 4,20 \\
MS & 0,77 & 85,00 & 57,68 & 87,67 \\
ALT & 3,75 & 8,73 & 7,58 & 1,03 \\
FLOR & 44,82 & 3,29 & 8,33 & 1,53 \\
AF & 2,87 & 0,15 & 3,42 & 1,87 \\
NF & 2,87 & 0,39 & 5,34 & 3,70 \\
\hline
\end{tabular}


primeira e segunda época de colheita (coeficiente de correlação positivo), e entre a primeira e quarta época de colheita (coeficiente de correlação negativo) (Tabela 4). Esses resultados também corroboram a importância da época de amostragem para estudos de divergência genética, e sugerem que a divergência genética deve ser estimada em cada época de colheita, separadamente.

TABELA 3. Distância de Mahalanobis $\left(D^{2}\right)$ intra e intergrupos entre nove acessos de mentrasto (Ageratum conyzoides), em quatro épocas de colheita.

\begin{tabular}{ccccc}
\hline Grupos & $\mathrm{I}$ & $\mathrm{II}$ & $\mathrm{III}$ & $\mathrm{IV}$ \\
\hline \multirow{4}{*}{$\mathrm{I}$} & $5,28(1)$ & 106,89 & - & - \\
& $84,36(2)$ & 245,78 & 338,58 & - \\
& $47,8(3)$ & 39,31 & 45,38 & 88,8 \\
& $34,02(4)$ & 226,51 & - & - \\
\hline \multirow{3}{*}{ II } & & 0 & - & - \\
& & 0 & 1000,09 & - \\
& & 0 & 95,05 & 48,06 \\
& & 0 & & - \\
\hline \multirow{3}{*}{ III } & & & - & - \\
& & & 0 & - \\
& & & - & - \\
\hline \multirow{3}{*}{ IV } & & & & - \\
& & & & - \\
& & & & - \\
\hline
\end{tabular}

(1) = colneıta realızada aos 21 dias apos transplante (dat); (2) = colheita realizada aos 42 dias após transplante (dat); (3) = colheita realizada aos 63 dias após transplante (dat); (4) = colheita realizada aos 84 dias após transplante (dat).

TABELA 4. Coeficientes de correlação (Spearman) das distâncias dos nove acessos de mentrasto entre quatro épocas de colheita.

\begin{tabular}{cccc}
\hline & 2ep & 3ep & 4ep \\
\hline 1ep & $0,5336^{* *}$ & $-0,1591^{\text {n.s. }}$ & $-0,2867^{*}$ \\
2ep & - & $-0,0528^{\text {n.s. }}$ & $-0,1604^{\text {n.s. }}$ \\
3ep & - & - & $0,2582^{\text {n.s. }}$ \\
\hline
\end{tabular}

1 ep = primeira época de colheita; 2 ep = segunda época de colheita; 3 ep = terceira época de colheita; 4 ep = quarta época de colheita; ns = não-significativo pelo teste "t" a $5 \%$ de probabilidade; ${ }^{* *}=$ significativo pelo teste " $\mathrm{t}$ " a $1 \%$ de probabilidade; ${ }^{*}=$ significativo pelo teste " $\mathrm{t}$ " a $5 \%$ de probabilidade.

\section{CONCLUSÃO}

Observou-se variação na constituição dos grupos pelos acessos de acordo com o estádio de desenvolvimento no qual a divergência genética foi estimada. Portanto, a divergência genética entre acessos de mentrasto, avaliada por caracteres morfológicos, é influenciada pelo estádio de desenvolvimento da espécie.

De forma geral, os acessos coletados na mesma região climática formaram grupo juntos. Este fato mostra a importância da coleta de germoplasma de $A$. conyzoides em diferentes regiões climáticas, com o objetivo de obter maior representatividade da variabilidade genética existente.

A característica massa seca foi a que mais contribuiu para a divergência genética entre os acessos na maior parte das épocas amostradas. Dessa forma, é recomendado incluir a característica massa seca como descritor morfológico em estudos de divergência genética de $A$. conyzoides.

Os acessos NAT e FOR que revelaram menor proximidade genética, com base na identificação morfológica de progenitores com alta divergência, podem ser selecionados para orientar cruzamentos no programa de melhoramento de $A$. conyzoides.

A existência de variabilidade entre os acessos coletados em diferentes localidades, fornece subsídio para a coleta sistematizada de germoplasma de $A$. conyzoides, em áreas abrangentes no Estado do Tocantins.

\section{REFERÊNCIA}

ABENA, A.A.; OUAMBA, J.M.; KEITA, A. Antiinflammatory, analgesic and antipyretic activities of essencial oil of Ageratum conyzoides. Phytotherapy Research, v.10, p.164-75, 1996.

ARRIEL, N.H.C. et al. Genetic divergence in sesame based on morphological and agronomic traits. Crop Breeding and Applied Biotechnology, v.7, n.3, p.253-61, 2007.

BENINCASA, M.M.P. Análise de crescimento de plantas. Jaboticabal: FUNEP, 1988. 42p.

BORTHAKUR, N.; BARUAH, A.K.S.; BHAGAT, S.D. Search for precocenes in Ageratum conyzoides Linn of northeast Índia. Journal Indian Chemistry Society, v.64, p.5801, 1987.

BOTREL, M.C.G. et al. Caracterização genética de Calophyum brasiliense Camb. em duas populações de mata ciliar. Revista Árvore, v.30, n.5, p.821-7, 2006.

CABRAL, B.L.R. et al. Isoenzymatic variability of cassava accessions from different regions in Brazil. Scientia Agricola, v.59, n.3, p.521-7, 2002.

CASTRO, H.G. et al. Estabilidade da divergência genética em seis acessos de carqueja. Planta Daninha, v.18, n.3, p.33-7, 2002.

CASTRO, H.G. et al. Teor e composição do óleo essencial de cinco acessos de mentrasto. Química Nova, v.27, n.1, p.55-7, 2004. 
CASTRO, H.G. et al. Stability of genetic divergence among five mentrasto accessions in two environments. Crop Breeding and Applied Biotechnology, v.5, n.3, p.332-8, 2005.

CASTRO, H.G. et al. Growth, content and composition of the essential oil of accessions of mentrasto (Ageratum conyzoides) collected in the state of Tocantins, Brazil. Revista Brasileira de Plantas Medicinais, v.10, n.2, p.3643, 2008.

CRUZ, C.D.; REGAZZI, A.J. Modelos biométricos aplicados ao melhoramento Genético. 2.ed. Viçosa: Universidade Federal de Viçosa, 1997. 390p.

GONZALEZ, A.G. et al. Chromenes from Ageratum conyzoides. Phytochemistry, v.30, n.4, p.1137-9, 1991. MAGALHÃES, J.F.G. et al. Analgesic and antiinflammatory activities of Ageratum conyzoides in rats. Phytotherapy Research, v.11, p.183-8, 1997.

MARQUES NETO, J.F. et al. Efeitos de "Ageratum conyzoides, Linee" no tratamento da artrose. Revista Brasileira de Reumatologia, v.28, n.4, p.109-14, 1988.
MENUT, C. et al. Aromatic plants of tropical central África. Part $x$ chemical composistion of the essential oils of Ageratum houstonianum Mill. and Ageratum conyzoides L. from Cameroom. Flavour and Fragance Journal, v.8, p.1-4, 1993.

OKUNADE, A.D. Ageratum conyzoides L. (Asteraceae). Fitoterapia, v.73, p.1-16, 2002.

RIBEIRO JÚNIOR, J.I. Análises estatísticas no SAEG. Viçosa: Universidade Federal de Viçosa, 2001. 301p. SECRETARIA DO PLANEJAMENTO E MEIO AMBIENTE. Diretoria de zoneamento ecológico-econômico. Atlas do Tocantins: subsídios ao planejamento da gestão territorial. 3.ed. Palmas: Seplan, 2003. 49p.

SILVA, D.J.H. et al. Stability of genetic divergence among eggplant accesses in three stages of development. Crop Breeding and Applied Biotechnology, v.1, n.2, p.135-43, 2001.

SINGH, D. The relative importance of characters affecting genetic divergence. Indian Journal Genetic and Plant Breeding, v.41, n.2, p.2237-45, 1981. 